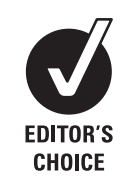

${ }^{1}$ Centre for Public Health, WHO Collaborating Centre for Violence Prevention, Liverpool John Moores University, Liverpool, UK; ${ }^{2}$ North West Public Health Observatory, Liverpool John Moores University, Liverpool, UK

Correspondence to:

Professor M A Bellis, Centre for Public Health, Liverpool John Moores University, Castle

House, North Street, Liverpool L3 2AY, UK;

m.a.bellis@ljmu.ac.uk

Accepted 28 March 2008 Published Online First

6 August 2008

\title{
Contribution of violence to health inequalities in England: demographics and trends in emergency hospital admissions for assault
}

\author{
M A Bellis, ${ }^{1} \mathrm{~K}$ Hughes, ${ }^{1}$ Z Anderson, ${ }^{1} \mathrm{~K}$ Tocque, ${ }^{2} \mathrm{~S}$ Hughes ${ }^{1}$
}

\section{ABSTRACT}

Introduction: Violence is increasingly recognised as a major public health issue yet health data are underutilised for describing the problem or developing responses. We use English emergency hospital admissions for assault over four years to examine assault demography and contribution to health inequalities.

Methods: Geodemographic cross-sectional analyses utilising records of all individuals in England ( $n=120$ 643) admitted between 1 April 2002 and 31 March 2006.

Results: Over 4 years, rates of admission increased by $29.56 \%$ across England. Admissions peaked on Saturdays (22.34\%) and Sundays (20.38\%). Higher rates were associated with deprivation across all ages, including those $<15$ years, with a sixfold increase in admission rates between the poorest and wealthiest quintiles of residence. Logistic regression analyses indicate males are 5.59 times more likely to be admitted to hospital for assault and such admissions peak in those aged 15-29 years. Modelling based on national assault admissions and limited Accident and Emergency (A\&E) data suggest that while more serious assaults requiring hospital admission have increased, assault attendances at A\&Es have fallen.

Discussion: Hospital admission and A\&E data identify a direct contribution made by violence to health inequalities. Levels of violence inhibit other interventions to improve people's health through, for instance, outdoor exercise or delivery of health-related services in affected areas. With disproportionate exposure to violence in poorer areas even in those under 15, early life primary prevention initiatives are required in disadvantaged communities to reduce childhood harm and the development of adult perpetrators and victims of violence.

Despite being considered primarily a judicial issue, violence, or the threat of violence, has major repercussions for the health of individuals and communities. ${ }^{12}$ Interpersonal violence is categorised into youth, sexual and intimate partner violence, child abuse and neglect, and elder abuse, ${ }^{1}$ with each type accounting for major costs to society in developed and developing countries. ${ }^{3}$ In England and Wales alone, annual costs of violence against adults (including violence against the person, sexual offences and common assault; excluding robbery) were estimated to be $£ 24.4$ billion in 2003. ${ }^{4}$ This includes costs to health services of $£ 2.2$ billion, which are comparable to, or in excess of, estimates for other recognised public health priorities such as obesity (up to $£ 1.2$ billion in 2002) ${ }^{5}$ and alcohol (up to $£ 1.7$ billion in 2000/ 01). ${ }^{6}$ Such costs arise from at least 2.5 million individuals being the victims of violence each year (England and Wales). ${ }^{7}$ Each assault can leave an individual scarred for life, physically disabled or psychologically affected and consequently unable to integrate and function as part of their family or community. More widely, fear of violence can imprison people within their homes, ${ }^{8}$ restrict children from outside play ${ }^{9}$ and discourage use of public transport. ${ }^{10}$ Consequently, violence not only impacts on the health of victims and perpetrators but also undermines efforts to improve health by increasing outdoor exercise and promoting social cohesion. Moreover, the ability for services to deliver support in communities is eroded by violence against visiting health personnel, ${ }^{11}$ and even staff in general practices, emergency units and hospital settings are at risk of violence by patients and their relatives. ${ }^{12}{ }^{13}$

While criminal justice services play a key role in policing affected areas and tackling offenders, the World Health Organization (WHO) has identified the fundamental role health services, and in particular public health, can play in primary and secondary prevention of violence. ${ }^{1}$ A public healthbased approach, however, requires a good understanding of the demographics of violence, opportunities for interventions with both victims and perpetrators (eg points of contact with health and other services), and individual risk and protective factors. Thus, international evidence suggests that experience of violence (as either a victim or perpetrator) disproportionately affects young males and individuals living in the most deprived sectors of society. ${ }^{14-16}$ In England and Wales, current understanding of demographics and trends in violence largely relies on the British Crime Survey (BCS) or police arrest data. ${ }^{7}$ The annual BCS is a household survey that provides key data on violence and identifies adults who are male, young, single, unemployed, and living in areas of high physical disorder as being at greater risk. However, it is limited in particular by age coverage (>15 years). In contrast, police arrest data provide complete national coverage but statistics are strongly influenced by policing priorities and resourcing, and exclude large proportions of violence that are not reported to police. ${ }^{17} 18$ Despite local initiatives (eg A\&E data monitoring systems $)^{1920}$ demonstrating the value of health intelligence in tackling violence through multisectoral approaches, no efforts have been made to utilise national health intelligence to understand patterns of assault or inform violence prevention strategies. 
Hospital Episode Statistics (HES) ${ }^{21}$ data routinely collected across England could provide a national data resource on assaults independent of police activity, covering all age groups, and capable of informing both health and judicial actions to prevent violence and limit its repercussions. Here, therefore, we examine all emergency hospital admissions for assaults in England between 1 April 2002 and 31 March 2006. We explore the demography of those affected, measure national trends in those assaults that are serious enough to require hospital admission and assess the impact of such violence on health services and wider public health initiatives. Further, we utilise novel geodemographic methodologies ${ }^{22}$ to characterise those ecologies most affected by violence and discuss the application of such methodologies for focusing multi-agency violence prevention strategies.

\section{METHODS}

The HES system warehouses all admissions (episodes of inpatient care under a hospital consultant) to National Health Service (NHS) hospitals in England, including private patients. ${ }^{21}$ Conditions are classified using the International Classification of Diseases 10 (ICD-10) ${ }^{23}$, which is capable of identifying admissions that were a result of assaults (X85-X99, Y00-Y09; all types of assaults including by bodily force, sharp object, blunt object, firearm, chemical or other means). Additional fields identify age at admission, sex, place of residence and method of admission (elective, emergency or other reasons), and a HES identification number allows different episodes relating to the same individual to be identified. For this study, only emergency admissions were selected and individuals were only counted once in each 12-month period. HES data are produced on a 1 April-31 March 12-month cycle, and numbers of individuals admitted as assault emergencies were 25789 (2002/03), 29204 (2003/04), $31710(2004 / 05)$ and 33940 $(2005 / 06)$. Complete data were not available for $2006 / 07$ at the time of analysis.

Individuals' place of residence was categorised from postcode to Lower Super Output Areas (LSOA; geographical areas (population mean $=1500$ ) designed to standardise reporting of small area statistics in England and Wales). For calendar years 2002 to 2004, the Office for National Statistics ${ }^{24}$ has calculated age and sex estimates of residence for each LSOA, which were used as denominators for assault frequencies for 2002/03, 2003/ 04 and 2004/05 respectively. However, only larger geographical population estimates were available for 2005 and, therefore, denominators for 2005/06 assaults utilised 2004 LSOA populations' age and sex adjusted to 2005 national population totals. For each LSOA a deprivation measure was also used, with the Index of Multiple Deprivation (IMD) $2004^{25}$ being chosen because of its general use in health profiling and inclusion of the most recent national census data. In addition, a geodemographic ecological classification was also calculated for each LSOA. Here, we applied the $\mathrm{P}^{2}$ (People \& Places 2) ${ }^{22}$ classification, which utilises clustering algorithms to define 14 area types, originally for the purposes of targeting advertising and commercial product sales. Unlike most other geodemographic systems, $\mathrm{P}^{2}$ classifications have been calculated for all English LSOA. ${ }^{26}$

To establish relationships between numbers of hospital admissions and attendances at Accident and Emergency (A\&E) departments, LSOA A\&E data were required over corresponding time periods. Residence-based A\&E data are not collected routinely in England. However, Wirral (Local Authority area, population approximately 313 500) has been collecting such data through the Trauma and Injury Intelligence Group (TIIG) ${ }^{19}$ and, as a peninsula, benefits from a relatively confined population covering a wide IMD range (LSOA IMD range; Wirral 4.60-79.73, England 0.59-86.36) and the vast majority of residents using its single $A \& E$ unit. ${ }^{18}$

Analyses examined the relative contributions of individual and ecological factors (ie residence area characteristics) to levels of violence and utilised chi square for comparison of rates, logistic regression to adjust for confounding effects and linear regression models to establish relationships between HES and A\&E data.

\section{RESULTS}

Over the 4-year period, the majority (58.94\%) of the 120643 assault admissions were bodily assaults, with those using a blunt weapon, sharp object, handgun or other assault type accounting for $8.73 \%, 14.37 \%, 0.13 \%$ and $17.94 \%$ respectively (assault types were categorised from HES external cause categories and any particular assault could be coded under more than one assault type). Further, admissions were significantly more likely to happen on Saturday or Sunday than on any other day of the week (Sunday to Saturday, $20.38 \%$, 13.34\%, 10.85\%, 10.01\%, $10.53 \%, 12.54 \%, 22.34 \%$; $\left.\chi^{2}=12681.27, \mathrm{p}<0.001\right)$. Over the period, rates of emergency hospital admission resulting from assaults increased across England as well as within every region (table 1).

However, regions differed significantly with the highest rate (North West) being 2.79 times higher than the lowest (East of England). Across England, rises in rates between 2002/03 and $2005 / 06$ represented a $29.56 \%$ increase. Moreover, significant increases occurred across all deprivation groups, age groups and both sexes. Consistent with other studies, emergency admissions data show males, those aged 15-44 and those in the most deprived areas being most likely to require treatment for assaults. Thus, in 2005/06, admission rates for males were 5.41 times higher than females, and for individuals living in the poorest quintile of deprivation 6.32 times higher than those in the most affluent (table 1). Although rates for those aged 15-44 were 6.87 times higher than for those aged $0-14$, even amongst this youngest age group there is already a strong increase in assault admissions with deprivation (table 1).

In order to better understand what types of communities are worst affected by violence and where interventions could be best placed, HES assault rates were examined by $\mathrm{P}^{2}$ categories. Consistent with deprivation effects, those living in Disadvantaged Households and Urban Challenge LSOAs suffer disproportionate levels of assault admission (table 2), with rates in the most affected groups (males aged 15-29) rising to around one admission per 128 people per year. In this age group, Blossoming Family areas equal the lowest rates of admission despite not being the most affluent areas (table 2).

However, geographic categories and other demographic variables are strongly linked and, therefore, in order to assess the individual contribution of each variable to assault hospital admissions, a multi-variate analysis was undertaken on 2004/05 data (table 3 ). Here, areas ( $\mathrm{P}^{2}$ categories) with high levels of deprivation remain most strongly linked with assaults, with those living in these ecologies being more than six times more likely to be admitted to hospital (cf the most affluent Mature Oaks; table 3). Again, admissions are over five times more likely to be men, with a strong concentration in those aged 15-29 (table 3). Region of residence is still a significant element in predicting assault admissions and even after correcting for the 
Table 1 Rates of emergency hospital admission for assault per 100000 residents per year stratified by individual and residence-based characteristics

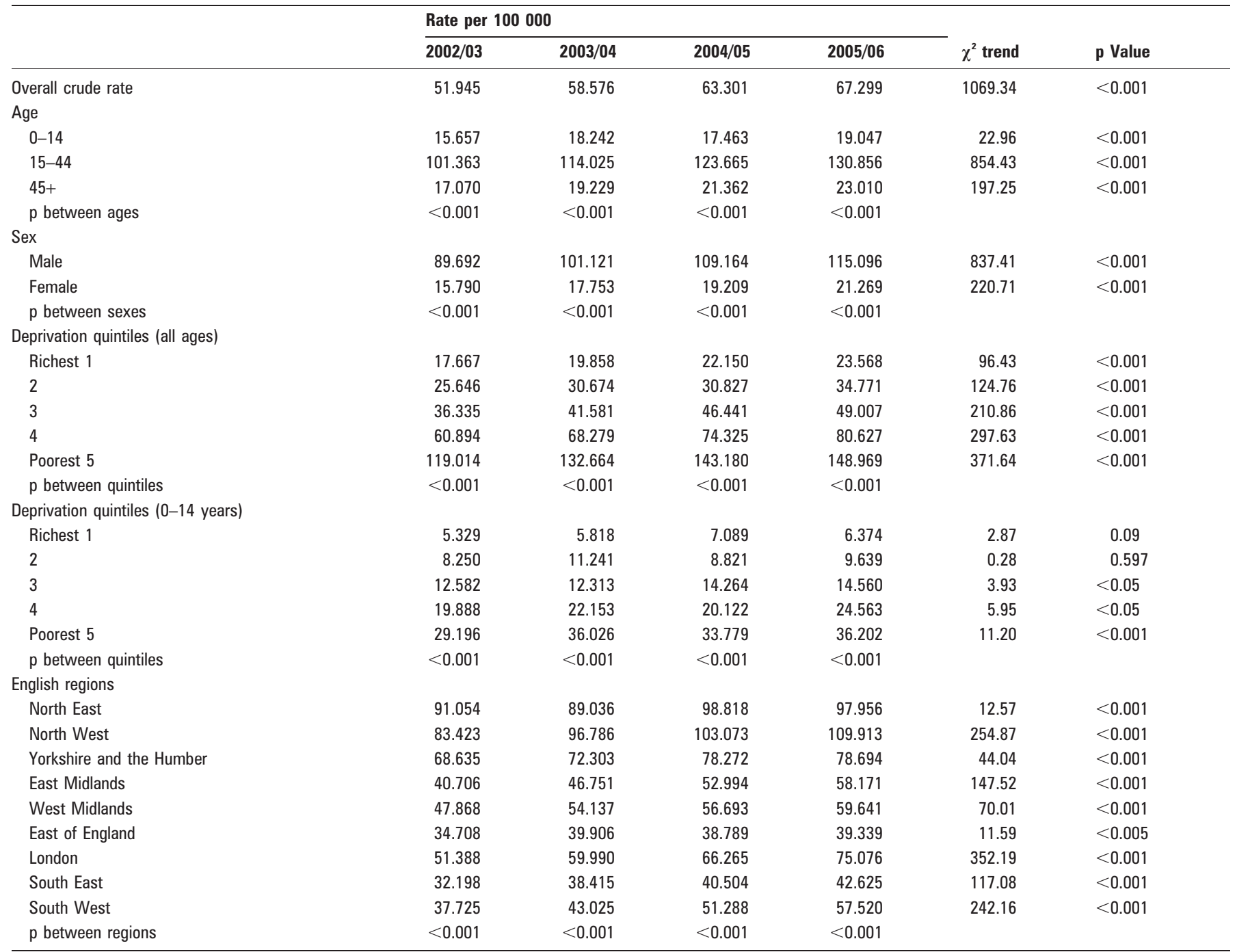

steep association with deprivation, the North West and North East regions still show the highest rates (table 3).

As hospital admissions will account for only a proportion of even those violent acts requiring medical treatment, we examined the relationship between hospital admissions and A\&E presentations for assault (fig 1). Despite analysis being limited to one local authority ( $\mathrm{n}=207$ LSOAs each year), there was a strong correlation $\left(\mathrm{r}^{2}=0.735, \mathrm{p}<0.001\right)$ between $\mathrm{A} \& \mathrm{E}$ presentations and hospital admissions (see fig 1). Applying the multiple regression model for Wirral to assault admissions for all English LSOAs, estimated annual A\&E presentations per 100000 are $642.85(\mathrm{n}=319153)$ in $2002 / 03,613.06$ $(\mathrm{n}=305650)$ in $2003 / 04,580.41(\mathrm{n}=290748)$ in $2004 / 05$ and $546.13(\mathrm{n}=275422)$ in $2005 / 06$, suggesting a $13.7 \%$ reduction in numbers over the study period.

\section{DISCUSSION}

Currently, there are no independent assessments of the clinical identification of assault as an external cause of hospital admission or the quality of its coding in HES. Consequently, specific geographies or national data as a whole may not fully represent all emergency hospital admissions for assault. Moreover, trends in data may also be influenced by differential access to hospitals, although access to such resources is often considered poorer amongst more deprived populations. ${ }^{27}$ HES data may also respond to changes in levels of hospital service provision although elective procedures are more likely to be affected (cf emergency admissions analysed here). For A\&E data, we were limited by having only temporally and geographically comparable data available for a relatively small area and, although this benefited from containing a varied and discrete population, the national representation of relationships between HES and A\&E data could not be tested. Finally, at least in part, our results rely on ecological analyses, hiding individual variations within each area classification. Again, however, we have utilised the smallest available geographies (LSOA) to minimise individual misclassifications. Consequently, we conclude that hospital data do provide an accessible dataset with complete geographical coverage, which is underutilised for examining assaults at national, regional and local levels. Such data are also largely independent from police activity with, in some areas, over $40 \%$ of assaults requiring health treatment not being reported to the police ${ }^{19}$ and even higher levels not appearing in recorded crime statistics. ${ }^{28}$ Moreover, as a longitudinal monitoring system, HES data are available routinely at geographies small enough to inform activities of local health, crime and other social services.

Utilising HES data identifies a significant (29.56\%) increase in assaults, severe enough to require hospital admission over the 
Table 2 Crude average* ${ }^{*}$ total population rates for emergency hospital admission for assault per 100000 residents per year and age-specific rates for males (15-44 years)

\begin{tabular}{|c|c|c|c|c|c|}
\hline \multicolumn{2}{|c|}{ People and Places geodemographic descriptions } & \multirow{2}{*}{$\begin{array}{l}\text { Average } \\
\text { IMD }\end{array}$} & \multicolumn{3}{|c|}{ Average annual rates per $100,000( \pm 95 \% \mathrm{Cl})$} \\
\hline Tree classification & Brief tree description $\dagger$ & & All assaults & Males $15-29$ years & Males $30-44$ years \\
\hline Mature Oaks & $\begin{array}{l}\text { Comprising wealthy, older working } \\
\text { people living in large detached houses } \\
\text { in rural areas }\end{array}$ & 6.81 & $19.46(19.45$ to 19.48$)$ & $139.29(138.75$ to 139.83$)$ & $37.17(36.97$ to 37.37$)$ \\
\hline Country Orchards & $\begin{array}{l}\text { Predominantly well-educated, high } \\
\text { income agricultural workers likely to } \\
\text { be self-employed }\end{array}$ & 7.62 & $29.74(29.72$ to 29.77$)$ & $163.29(162.68$ to 163.90 & $47.73(47.51$ to 47.95$)$ \\
\hline Blossoming Families & $\begin{array}{l}\text { Typified by well qualified, and well } \\
\text { paid, young professional families with } \\
\text { infants - buying detached houses }\end{array}$ & 13.86 & $20.31(20.29$ to 20.34$)$ & 139.32 (138.49 to 140.16$)$ & 45.21 (44.90 to 45.52$)$ \\
\hline Rooted Households & $\begin{array}{l}\text { Largely skilled manual workers, quite } \\
\text { high income, buying semi-detached } \\
\text { houses }\end{array}$ & 12.11 & 34.36 (34.34 to 34.38$)$ & 205.87 (205.36 to 206.38) & $68.26(68.04$ to 68.47$)$ \\
\hline Qualified Metropolitans & $\begin{array}{l}\text { Largely highly qualified professional } \\
\text { commuters living in small single } \\
\text { households concentrated in city centres }\end{array}$ & 13.98 & 33.31 (33.28 to 33.34$)$ & $200.40(199.40$ to 201.40$)$ & $90.92(90.40$ to 91.45$)$ \\
\hline Senior Neighbourhoods & $\begin{array}{l}\text { Characterised by quite affluent older } \\
\text { people or pensioners living in } \\
\text { owner-occupied detached houses; } \\
\text { likely to own a second home }\end{array}$ & 17.68 & 46.81 (46.78 to 46.85$)$ & 144.88 (144.41 to 145.35$)$ & 85.67 (85.36 to 85.97$)$ \\
\hline Suburban Stability & $\begin{array}{l}\text { Predominantly skilled manual, routine } \\
\text { and semi-routine workers living in } \\
\text { semi-detached and terraced housing }\end{array}$ & 20.00 & $55.37(55.35$ to 55.40$)$ & $278.60(278.05$ to 279.15$)$ & $124.62(124.32$ to 124.91$)$ \\
\hline New Starters & $\begin{array}{l}\text { Primarily students and highly qualified, } \\
\text { but low income, young adults living in } \\
\text { single or cohabiting bedsits or flats }\end{array}$ & 29.78 & 96.52 (96.45 to 96.59$)$ & 235.77 (235.18 to 236.36$)$ & 215.34 (214.64 to 216.04$)$ \\
\hline Multicultural Centres & $\begin{array}{l}\text { Characterised by semi-skilled, unskilled } \\
\text { and unemployed Jewish, Muslim, } \\
\text { Black, Chinese, Indian, Pakistani and } \\
\text { Bangladeshi low income families } \\
\text { living in terraces }\end{array}$ & 34.34 & 92.75 (92.71 to 92.79 ) & 420.04 (419.22 to 420.86$)$ & $223.53(223.01$ to 224.04$)$ \\
\hline Urban Producers & $\begin{array}{l}\text { Mainly semi-skilled, unskilled, } \\
\text { unemployed and unqualified single } \\
\text { parents living in terraced council } \\
\text { housing with low incomes }\end{array}$ & 37.70 & 101.53 (101.48 to 101.59$)$ & 450.48 (449.37 to 451.59 ) & 267.02 (266.26 to 267.77$)$ \\
\hline Weathered Communities & $\begin{array}{l}\text { Unemployed, low income pensioners } \\
\text { or lone parent families with routine or } \\
\text { semi-routine occupations in semi-detached } \\
\text { housing or purpose built flats }\end{array}$ & 41.07 & 103.03 (102.98 to 103.09$)$ & 327.06 (326.43 to 327.69$)$ & $220.14(219.57$ to 220.71$)$ \\
\hline Disadvantaged Households & $\begin{array}{l}\text { Predominantly low income, poorly } \\
\text { qualified young families or lone parents } \\
\text { living in council or housing association } \\
\text { homes }\end{array}$ & 53.71 & $170.32(170.21$ to 170.42$)$ & 690.20 (688.43 to 691.97$)$ & $448.70(447.27$ to 450.13$)$ \\
\hline Urban Challenge & $\begin{array}{l}\text { Typified by unemployed, low income } \\
\text { older people living in small council or } \\
\text { housing association homes }\end{array}$ & 61.93 & 235.98 (235.77 to 236.18 ) & 778.08 (775.24 to 780.92$)$ & $656.10(653.45$ to 658.75$)$ \\
\hline Unclassified & $\begin{array}{l}\text { Small number of Lower Super Output } \\
\text { Areas that could not be statistically } \\
\text { classified into } \mathrm{P}^{2} \text { categories }\end{array}$ & 25.09 & 71.11 (70.97 to 71.25$)$ & 262.99 (261.26 to 264.72 ) & $138.38(137.22$ to 139.55$)$ \\
\hline $\mathrm{P}$ & Comparisons between tree classifications & $<0.001$ & $<0.001$ & $<0.001$ & $<0.001$ \\
\hline
\end{tabular}

*Rates and confidence intervals for each classification are calculated using each LSOA as individual data points; data for all years 2002/03 to 2005/06 are included and averaging utilises LSOA population-based weightings.

$\dagger \mathrm{P}^{2}$ People and Places is a geodemographic classification system developed for market segmentation. ${ }^{22}$ Descriptions provided in this table are abbreviated from the Full Tree Classification.

IMD, Index of Multiple Deprivation.

study period. Over approximately the same period, the British Crime Survey identified a steady decrease in violent crime $(14 \%$ between 2002/03 and 2005/06 interviews). ${ }^{29}$ A similar decrease has also been seen in assault presentations to some $A \& E$ departments. $^{20}$ In contrast, between 2002/03 and 2005/06, police recorded crime figures for violence against the person offences increased by $25 \%{ }^{29}$ The BCS has shown that victims are more likely to report violence to police if it is serious, causes injury, and if the injury sustained is more severe (eg intimate partner violence)..$^{30}$ Thus, rising HES violence suggests more serious violence is increasing, and helps explain the divergence in violence figures reported through police data and those through the BCS and A\&E monitoring systems, which also include less serious incidents of violence involving no (BCS) and minor (BCS and $A \& E$ ) injuries that may not require hospital admission. Importantly, HES data allow estimates and trends analyses based on specific geodemographics. Thus, assaults disproportionately affect the poorest with rates being consistently more than six times higher in the most deprived compared with the most affluent quintile of deprivation (table 1). Moreover, using HES data, we identified this relationship as already apparent in those aged under 15 years (table 1). Critically, evidence suggests that exposure to violence (as a perpetrator or victim) is strongly related to long-term negative health and social outcomes throughout life. Thus, those exposed to violence (eg child abuse) are not only more likely to experience violence later in 
Table 3 Logistic regression analyses of emergency hospital admissions for assaults utilising individual and residence-based characteristics for individuals resident in England admitted in 2004/05*

\begin{tabular}{|c|c|c|}
\hline & Adjusted odds ratio $95 \% \mathrm{Cl}$ (lower to upper) & p Value \\
\hline \multicolumn{3}{|l|}{ Sex } \\
\hline Female (Ref) & 1.000 & \\
\hline Male & 5.585 (5.417 to 5.757$)$ & $<0.001$ \\
\hline \multicolumn{3}{|l|}{ Age category } \\
\hline 0-14 (Ref) & 1.000 & \\
\hline $15-29$ & 9.476 (8.999 to 9.978$)$ & $<0.001$ \\
\hline $30-44$ & 5.309 (5.034 to 5.598$)$ & $<0.001$ \\
\hline 45 and over & 1.446 (1.365 to 1.532$)$ & $<0.001$ \\
\hline \multicolumn{3}{|l|}{ People \& Places category $\dagger$} \\
\hline Mature Oaks (Ref) & 1.000 & \\
\hline Country Orchards & 1.315 (1.212 to 1.427$)$ & $<0.001$ \\
\hline Blossoming Families & $1.042(0.946$ to 1.148$)$ & 0.405 \\
\hline Rooted Households & 1.578 (1.477 to 1.687$)$ & $<0.001$ \\
\hline Qualified Metropolitans & 1.694 (1.553 to 1.848$)$ & $<0.001$ \\
\hline Senior Neighbourhoods & 1.745 (1.611 to 1.890$)$ & $<0.001$ \\
\hline Suburban Stability & 2.469 (2.319 to 2.629$)$ & $<0.001$ \\
\hline New Starters & 3.135 (2.924 to 3.361$)$ & $<0.001$ \\
\hline Multicultural Centres & 3.889 (3.654 to 4.138$)$ & $<0.001$ \\
\hline Urban Producers & 4.238 (3.969 to 4.525$)$ & $<0.001$ \\
\hline Weathered Communities & 3.876 (3.623 to 4.147$)$ & $<0.001$ \\
\hline Disadvantaged Households & 6.617 (6.191 to 7.072$)$ & $<0.001$ \\
\hline Urban Challenge & 7.687 (7.129 to 8.289$)$ & $<0.001$ \\
\hline Unclassified & 2.896 (2.571 to 3.263 ) & $<0.001$ \\
\hline \multicolumn{3}{|l|}{ English Regions } \\
\hline North East (Ref) & 1.000 & \\
\hline North West & 1.118 (1.068 to 1.171$)$ & $<0.001$ \\
\hline Yorkshire and the Humber & 0.857 (0.815 to 0.901$)$ & $<0.001$ \\
\hline East Midlands & 0.679 (0.641 to 0.719$)$ & $<0.001$ \\
\hline West Midlands & $0.654(0.620$ to 0.690$)$ & $<0.001$ \\
\hline East of England & $0.618(0.583$ to 0.655$)$ & $<0.001$ \\
\hline London & $0.707(0.671$ to 0.745$)$ & $<0.001$ \\
\hline South East & 0.661 (0.627 to 0.697$)$ & $<0.001$ \\
\hline South West & 0.810 (0.766 to 0.857$)$ & $<0.001$ \\
\hline
\end{tabular}

Ref, Reference category; $95 \% \mathrm{Cl}$, 95\% confidence intervals.

*Data included all individuals admitted to hospital for assault in England in 2004/05. Data for individuals not requiring such admissions were calculated by subtraction of admitted individuals from age- and sex-specific populations in each Lower Super Output Area. Only 2004/05 data were utilised in the model to avoid pseudo-replication of population data, with 2004/05 being chosen as it was closest to the latest national census projection and consequently provides best population estimates.

†Due to the strong correlation between People and Places $\left(\mathrm{P}^{2}\right)$ categories and Index of Multiple Deprivation (IMD; table 2).

$\mathrm{P}^{2}$ categories were also utilised as proxy for deprivation and, therefore, deprivation quintiles were not entered into the model as a separate variable.

life ${ }^{3132}$ but are also at increased risk of sexually transmitted infections, obesity and depression, and even conditions such as cancer and coronary heart disease. ${ }^{33} 34$

Effective, evidence-based interventions have already been developed to reduce levels of violence and development of violent tendencies through work in schools and directly with parents and children. Such programmes can aim to universally develop social and relationship skills in children (eg Promoting Alternative Thinking Strategies (PATHS), ${ }^{35}$ the Fourth R), ${ }^{36}$ or provide targeted support to children and parents at most risk of aggression, to develop parenting skills and strengthen family relationships (eg Triple P). ${ }^{37}$ Over and above targeting by deprivation, we have shown that HES assault data can be used to identify small community types most affected by violence through the use of marketing population segregation techniques (table 2). This technique, for instance, identifies Urban Challenge communities as most at risk. Moreover, such ecologies can provide information on how to reach members of such communities (eg which newspapers they read, where they shop and what leisure activities they engage in). ${ }^{22}$ Such techniques have been routinely exploited in commercial marketing but their application to social marketing for the targeting of both health interventions and positioning of positive messages is only just being developed. ${ }^{26}{ }^{38}$ However, services already have access, through routine (eg maternity) and specialist early years programmes (eg SureStart), to mothers and children in deprived areas. Adapting these programmes to ensure they can identify violence and associated factors (eg substance use), minimise violence and prevent development of aggressive behaviour in children should be a health and criminal justice priority, especially in Urban Challenge and Disadvantaged Households areas (table 2). In effect, services can and should provide an early immunisation against the development of violent behaviour, just as we seek to protect against childhood diseases.

Unfortunately, delivering services to the most violent communities is already a challenge with health and other visiting workers frequently threatened and assaulted. ${ }^{12}{ }^{39}$ Such work requires multi-agency partnership at local levels. Here, agencies should exchange data on where violence is most prevalent and more broadly support each other in the delivery of interventions aimed at identifying perpetrators, ${ }^{40}$ providing 


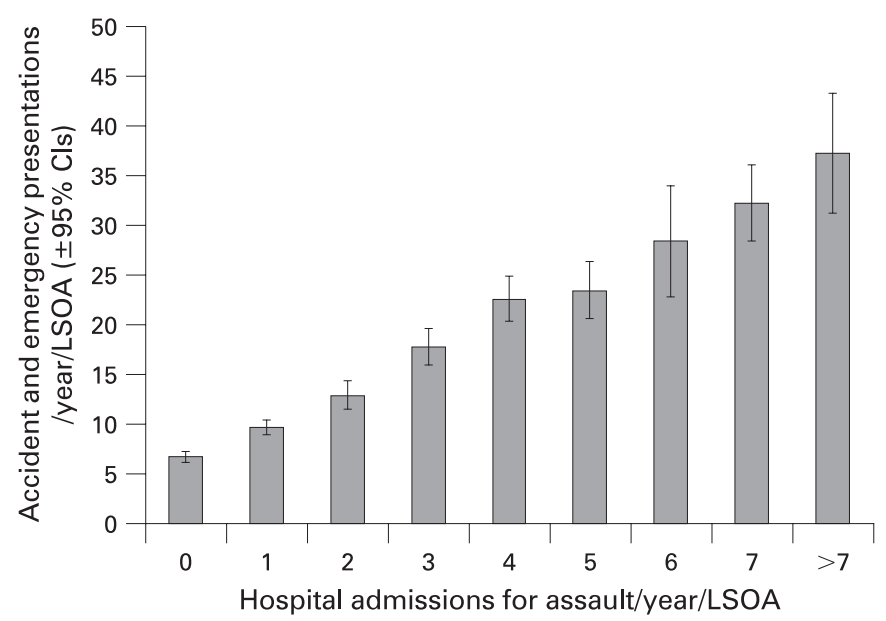

Figure 1 Relationship between annual number of hospital admissions for assault per Lower Super Output Area and number of presentations for assault at Accident and Emergency. Bars and lines represent mean ( $\pm 95 \% \mathrm{Cl}$ ) number of Accident and Emergency presentations seen per year by LSOA (Lower Super Output Area). Data cover 4 years from 2002/ 03-2005/06 and are limited to Wirral Local Authority $(n=207$ LSOA each year). Estimated national numbers for Accident and Emergency presentations were calculated using the same data in a populationweighted linear multiple regression at LSOA level with Index of Multiple Deprivation (IMD), year $(2002 / 03=1$ to $2005 / 06=4)$, and HES assault admissions as independents $\left(\mathrm{r}^{2}=0.730\right.$, all terms independently significant at $p<0.001)$. Least squares regression,

A\&E $=3.054+\left(\right.$ HES $\left.^{*} 1.532\right)+\left(\right.$ IMD* $\left.^{*} 0.283\right)+\left(\right.$ Year $\left.^{*}-0.577\right)$.

proactive interventions where violence is likely to occur and addressing the underlying determinants of violent behaviour. Health data can form part of an intelligence suite along with locally recorded crime and broader intelligence from surveys like the BCS. Such intelligence should underpin activities of multi-agency partnerships to reduce crime and its impact on health (eg English Crime and Disorder Reduction Partnerships), allowing targeted intervention and appropriate evaluation. Additional bespoke health intelligence may also be available in some localities. Thus, here we have estimated that A\&E units across England could contribute intelligence on around 300000 assaults each year; many of which will not result in someone being admitted into hospital. However, while such data have been successfully used to target policing at where assaults take place, their application to identifying communities where violent individuals reside is less well developed. ${ }^{16}$ Using limited residential A\&E data, our analyses suggest overall patterns (ie rates of attendance) are broadly consistent with HES admissions (fig 1). Moreover, trends in national estimates for $\mathrm{A} \& \mathrm{E}$ calculated here are consistent with data for other parts of England and Wales suggesting a slight recent decline in $\mathrm{A} \& \mathrm{E}$ attendance for assaults (this study change 2002/03-2005/06, $13.7 \%$ reduction; national A\&E collective, 2002-2005, 14.7\% reduction). Such reductions are also consistent with those shown in the BCS. ${ }^{29}$ Finally, although HES data do not allow specific analyses of relationships with alcohol seen in other assault datasets, ${ }^{19}{ }^{29}$ analysis of day of presentation shows a strong peak in assault admissions at weekends consistent with an influential role being played by alcohol and nightlife. ${ }^{41}$ Thus, wherever possible, victims and perpetrators should be routinely investigated for alcohol problems and appropriate referrals made to specialist support services and brief interventions. ${ }^{42}$

\section{CONCLUSIONS}

The difference in wealth between the best- and worst-off in the UK has increased to a 40 -year high. ${ }^{43}$ Furthermore, despite targets created to reduce health inequalities, differences in life expectancy and other health measures between deprived and affluent communities are also increasing. ${ }^{44}$ Our analyses suggest that violence is strongly related to deprivation gradients and that serious violence is increasing across England (table 1-3). The direct contribution violence makes to health inequalities is likely to be significant, with around 30000 mainly poorer individuals requiring emergency hospital admissions each year, ten times that number presenting at A\&E (fig 1), and numerous more assaults presenting at general practices or being treated through self-medication..$^{30}$ However, violence is also a major inhibitor of general public interventions, with fear and insecurity increasing stress and limiting individuals to a sedentary lifestyle trapped within their homes. Unless such violence is tackled, other public health efforts to address for instance alcohol or obesity are unlikely to be successful in the poorest communities. Tackling such violence requires a multi-agency approach underpinned by shared intelligence. Our analyses suggest that hospital data provide additional information capable of identifying the specific communities (eg geodemographic classifications; table 3) most affected. They also highlight the pressures violence already exerts on health systems and the frequency that health service staff deal with not only victims but also perpetrators of violence. However, such contacts represent relatively unexploited opportunities both to identify perpetrators and to prevent re-offence. In such circumstances, the required multi-agency response is still too often inhibited by lack of clarity over the exchange of person-specific information between health and judicial systems.

Regardless of policing and secondary prevention initiatives, the necessary reductions in violence required in the most deprived communities can only be made through successful primary prevention efforts. Even in those aged 14 and under, there is already a five times higher rate of assault admissions in the poorest compared to the richest quintiles of residence (table 1). Such violence is not only destructive to short- and long-term health, but also acts as an incubator for the development of violent adults and those more likely to be abused in later life. Early life interventions can prevent violence against and between children and reduce development of violent tendencies in youths and adults. Implementing such interventions may require accepting a longer timeframe for benefits to be recouped. However, continuing to focus on a punitive approach may only add to the increasing trends in assault admissions identified here and substantially undermine wider efforts to improve the health of the most deprived.

Acknowledgements: We are grateful to Sacha Wyke for support accessing and organising the datasets utilised in this analysis. Comments on this manuscript by Michela Morleo and Dan Hungerford helped improve upon earlier versions. Finally, we would also like to thank the Trauma and Injury Intelligence Group for utilisation of their Accident and Emergency (A\&E) data and the staff at Arrowe Park A\&E for their continued efforts in collecting and sharing such intelligence.

Contributors: MAB designed the study, analysed and interpreted the data, and wrote the manuscript. $\mathrm{KH}$ conducted background literature reviews and edited the paper. ZA and $\mathrm{SH}$ assisted with literature reviews and edited the paper. KT extracted the data, assisted with data analyses and edited the paper.

Competing interests: None 


\section{What this study adds}

- A judicial approach to tackling violence has led to crime survey or police arrest data being the mainstay for demographic and temporal analyses of violence and its effects on communities.

- We show how a national system for collecting emergency hospital admissions data allows independent analysis of demographic and temporal trends in violence and their impact on health inequalities.

- Results indicate a strong positive relationship between violence serious enough to require hospital admission and deprivation. Moreover, this relationship is already apparent in those under 15 years old.

- Admissions to hospital have increased in the past 4 years suggesting levels of serious violence are increasing. However, data modelling suggests presentations to A\&E may be falling, consistent with reductions in numbers of less severe violent acts.

- Approaches to tackling violence aimed at adults who have already developed violent tendencies are unlikely to be effective at reducing serious violence in the long term and a much stronger focus on early life prevention initiatives is required, especially in disadvantaged communities.

\section{REFERENCES}

1. Krug EG, Dahlberg LL, Mercy JA, et al. World report on violence and health. Geneva: World Health Organization 2002.

2. McVeigh C, Hughes K, Bellis MA, et al. Violent Britain: people, prevention and public health. Liverpool: Centre for Public Health, Liverpool John Moores University, 2005.

3. Waters $\mathbf{H}$, Hyder A, Rajkotia $Y$, et al. The economic dimensions of interpersonal violence. Geneva: World Health Organization, 2004

4. Dubourg R, Hamed J. Estimates of the economic and social costs of crime in England and Wales: costs of crime against individuals and households, 2003/04. Home Office online report 30/05. London: Home Office, 2005. http://www. homeoffice.gov.uk/rds/pdfs05/rdsolr3005.pdf (accessed 29 Aug 2007).

5. Select Committee on Health. Third Report, Annex 1: The economic costs of obesity: a note prepared by the Scrutiny Unit, Clerk's Department, House of Commons. London: House of Commons, 2004. http://www.parliament.the-stationery-office.co. uk/pa/cm200304/cmselect/cmhealth/23/2302.htm (accessed 29 Aug 2007).

6. Strategy Unit. Alcohol harm reduction project interim analytical report. London: Strategy Unit, 2003

7. Jansson K, Povey D, Kaiza P. Violent and sexual crime. In: Nicholas S, Kershaw C, Walker A, ed. Crime in England and Wales 2006/07, 2nd edition. London: Home Office, 2007:49-72

8. Margo J, Dixon M, Pearce N, et al. Freedom's orphans: raising youth in a changing world. London: Institute for Public Policy Research, 2006.

9. Weir LA, Etelson D, Brand DA. Parents' perceptions of neighborhood safety and children's physical activity. Prev Med 2006;43:212-17.

10. Crime Concern. People's perceptions about personal security and their concerns about crime on public transport. London: Department for Transport, 2004 http://www. dft.gov.uk/pgr/crime/ps/perceptions/researchfindings (accessed 29 Aug 2007).

11. Royal College of Nursing. At breaking point? A survey of the wellbeing and working lives of nurses in 2005. London: Royal College of Nursing, 2006.

12. Health Care Commission. National survey of NHS staff 2006. http://www. healthcarecommission.org.uk/nationalfindings/surveys/staffsurveys/ 2006nhsstaffsurvey.cfm (accessed 6 Aug 2007)

13. Magin PJ, Adams J, Sibbritt DW, et al. Experiences of occupational violence in Australian urban general practice: a cross-sectional study of GPs. Med J Aust 2005; 183:352-56.

14. Hsieh C, Pugh MD. Poverty, income inequality and violent crime: a meta-analysis of recent aggregate data studies. Criminal Justice Review 1993;18:182-202.

15. MacDonald S, Cherpitel CJ, Borges G, et al. The criteria for causation of alcohol in violent injuries based on emergency room data from six countries. Addict Behav 2005;30:103-13.

16. Howe A, Crilly M. Deprivation and violence in the community: a perspective from a UK Accident and Emergency Department. Injury 2001;32:349-51.

17. Shepherd J, Sivarajasingam V. Injury research explains conflicting violence trends Inj Prev 2005:11:324-25.

18. Bellis MA, Anderson Z, Hughes K. Effects of the Alcohol Misuse Enforcement Campaigns and the Licensing Act 2003 on Violence. Liverpool: Centre for Public Health, Liverpool John Moores University, 2006.

\section{Policy implications}

- With violence a major factor in deprived areas, efforts to increase exercise and reduce alcohol and drug use are likely to be of only limited success. Consequently, policy aimed at tackling health inequalities must also address the need for safer communities and family environments.

- Experience of violence is already disproportionately high in poorer communities by the age of 14 . Interventions are urgently required to ensure childhood exposure to violence is minimised. Such interventions will not only reduce health and social problems in young people but also contribute to better adult health through reduced risk of suicide, cancer and coronary heart disease.

- In order to ensure localities have the best possible data available to tackle violence, clear guidance on the exchange of data, especially between health and judicial agencies, is required at individual and aggregate data levels.

- Multi-agency data should be central in the development of local strategies to prevent violence and, along with punitive measures, such strategies must include primary prevention and support for victims, and should address all life stages from conception onwards.

19. Trauma and Injury Intelligence Group. http://www.nwpho.org.uk/ait/ (accessed 25 July 2007).

20. Sivarajasingam V, Moore S, Shepherd JP. Violence in England and Wales 2006: an accident and emergency perspective. Cardiff: Violence Research Group, Cardiff University, 2007.

21. The Information Centre. Hospital Episode Statistics online. http://www.hesonline. nhs.uk (accessed 31 Aug 2007).

22. Beacon Dodsworth. P2 People and Places: using geography to classify people by where they live. York: Beacon Dodsworth Ltd, 2005.

23. World Health Organization. The international statistical classification of diseases and related health problems, 10th revision. Geneva: World Health Organization, 1992.

24. Office for National Statistics. Super Output Area mid-year population estimates for England and Wales (experimental). http://www.statistics.gov.uk/StatBase/Product. asp? vInk = 14357\&Pos = \&ColRank = 2\&Rank =960 (accessed 20 Aug 2007)

25. Noble M, Wright G, Dibben C, et al. The English indices of deprivation 2004 (revised) London: Neighbourhood Renewal Unit, 2004.

26. Dedman D, Jones A, Tocque K, et al. Population marketing: tools for social marketing. Liverpool: North West Public Health Observatory, 2006.

27. Department of Health. Tackling health inequalities: a programme for action. London: Department of Health Publications, 2003.

28. Sutherland I, Sivarajasingam V, Shepherd JP. Recording of community violence by medical and police services. Inj Prev 2002;8:246-47.

29. Walker A, Kershaw C, Nicholas S. Crime in England and Wales, 2005/06. London: Home Office, 2006.

30. Walby S, Allen J. Domestic violence, sexual assault and stalking: findings from the British Crime Survey. London: Home Office, 2004

31. Schaaf KK, McCanne TR. Relationship of childhood sexual, physical, and combined sexual and physical abuse to adult victimization and post-traumatic stress disorder. Child Abuse Negl 1998;22:1119-33.

32. Sourander A, Jensen $P$, Rönning JA, et al. Childhood bullies and victims and their risk of criminality in late adolescence. Arch Pediatr Adolesc Med 2007;161:546-52.

33. Felitti VJ, Anda RF, Nordenberg D, et al. Relationship of childhood abuse and household dysfunction to many of the leading causes of death in adults. Am J Prev Med 1998;14:245-58.

34. Dube SR, Felitti VJ, Dong M, et al. The impact of adverse childhood experiences on health problems: evidence from four birth cohorts dating back to 1900. Prev Med 2003:37:268-77.

35. Domitrovich CE, Cortes RC, Greenberg MT. Improving young children's social and emotional competence: a randomized trial of the preschool "PATHS" curriculum. J Prim Prev 2007;28:67-91.

36. Wolfe DA. Preventing violence in relationships: psychological science addressing complex social issues. Can Psychol 2006;47:44-50.

37. Turner KMT, Sanders MR. Dissemination of evidence-based parenting and family support strategies: learning from the Triple $\mathrm{P}$ - Positive Parenting Program system approach. Aggression and Violent Behavior 2006;11:176-93.

38. Department of Health. Choosing health: making healthier choices easier. London: The Stationery Office, 2004. 
39. Department for Communities and Local Government. Tackling violence at work: good practice guidance document for fire and rescue services. London: Department for Communities and Local Government, 2007.

40. Counter Fraud and Security Management Service. NHS and police get tough on violence against NHS staff. Press release 15 August 2006. http://www.cfsms.nhs.uk/ doc/press.release/pr.sms.mou.with.acpo.08.06.pdf (accessed 6 Aug 2007).

41. World Health Organization. Youth violence and alcohol. Geneva: World Health Organization, 2006.
42. Babor TF, Higgins-Biddle JC. Brief interventions for hazardous and harmful drinking: a manual for use in primary care. Geneva: World Health Organization 2001

43. Dorling D, Rigby J, Wheeler B, et al. Poverty, wealth and place in Britain 1968-2005 Findings. York: Joseph Rowntree Foundation, 2007.

44. Department of Health. Tackling health inequalities: 2003-05 data update for the National 2010 PSA Target. London: Department of Health, 2006 http://www.dh.gov uk/en/Publicationsandstatistics/Publications/PublicationsStatistics/DH 063689 (accessed 20 Aug 2007).

\section{BMJ Masterclasses}

BMJ Masterclasses are educational meetings designed specifically to meet the learning needs of doctors. They help doctors keep up to date with the latest evidence and recent guidelines in major clinical areas, enabling them to use the latest evidence to make better decisions. The latest evidence, recent guidelines and best practice are delivered in an interactive and informative manner by leading experts. The speakers are specifically chosen as highly-skilled communicators who can authoritatively enthuse the audience and interpret the latest research and guidelines into practical tips for busy doctors. BMJ Masterclasses have proved a huge hit with clinicians, with many saying they have influenced their clinical practice.

http://masterclasses.bmj.com/ 